\title{
An Online Tutorial Vs. Pre-Recorded Lecture For Reducing Incidents Of Plagiarism
}

\author{
Amber M. Henslee, Ph.D., Missouri University of Science and Technology, USA \\ Jacob Goldsmith, B.S., Florida Atlantic University, USA \\ Nancy J. Stone, Ph.D., Missouri University of Science and Technology, USA \\ Merilee Krueger, M.A., Missouri University of Science and Technology, USA
}

\begin{abstract}
The current study compared an online academic integrity tutorial modified from Belter \& du Pre (2009) to a pre-recorded online academic integrity lecture in reducing incidents of plagiarism among undergraduate students at a science and technology university. Participants were randomized to complete either the tutorial or the pre-recorded lecture and then completed an academic integrity quiz. We hypothesized that students who completed the tutorial would exhibit fewer incidents of plagiarism and complete the quiz with fewer attempts. Results revealed no statistically significant difference in incidents of plagiarism between the groups. There was a significant positive relation between the number of quiz attempts and the incidents of plagiarism ( $r$ $(31)=.388, p=.03)$. Results suggest that an online tutorial is equally effective as a pre-recorded online lecture in addressing issues of plagiarism in the classroom. These results are discussed in the context of education strategies, intrinsic motivation, and time-saving methods.
\end{abstract}

Keywords: Plagiarism; Academic Integrity College Students

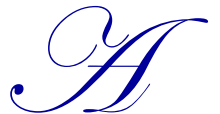

cademic dishonesty can consist of cheating, plagiarism, or misconduct. The prevalence of these behaviors among college students has increased significantly in the past 30 years (McCabe, Trevino \& Butterfield, 2001; Yeo, 2007). Research suggests that more than half of all college undergraduates engage in some form of academic dishonesty (Newstead, Franklyn-Stokes, \& Armstead, 1996). Furthermore, academic dishonesty may vary by discipline (Yeo, 2007). Engineering has the highest levels of cheating, and cheating of all kinds (i.e., including plagiarism) was found to be most common in the science and technology fields (Newstead, Franklyn-Stokes, \& Armstead, 1996).

Among the different types of academic dishonesty, it is likely that plagiarism is more common than reported (Yeo, 2007). Parameswaran \& Devi (2006) reported that plagiarism is at especially disturbing levels in undergraduate engineering labs. In fact, acts such as copying lab reports seems to have become the norm, and not a single upperclassman denied copying some previous academic work.

The act of plagiarism affects many individuals. Plagiarism is defined as representing the work of another as your own (Barrett \& Cox, 2005). From this definition it can be inferred that the individual having his or her work plagiarized is being affected, as well as the individual who is stealing the work. Clearly, the individuals who plagiarize are harming themselves by not engaging in the educational process and learning the material. Furthermore, this behavior may precipitate a type of denial in the students, in that many students later do not classify their actions as plagiarism or they construct excuses to make their acts appear less reprehensible (Parameswaran \& Devi, 2006).

Faculty and the institution as a whole are impacted by plagiarism as well. Faculty must face several difficult decisions, specifically whether to ignore the plagiarism (i.e., reward the plagiarism—clearly not a 
preferable option) or punish the act. While most faculty would likely adhere to their institutional guidelines regarding academic dishonesty, it may be very difficult and time consuming to prove that plagiarism has taken place (i.e., finding the original source material, processing paperwork to formally charge a student with plagiarism) (McKeachie, 2002). Furthermore, if faculty decide to address the problem, they then face the possibility of anger and/or denial on the part of the student including a potential legal defense (especially if institutional rules of action were not followed) (McKeachie, 2002).

Academically dishonest behavior in recent media stories, such as the Harvard cheating scandal, suggests that this behavior can mar the reputation of even the most prestigious institutions (Pérez-Peña, 2012). It is plausible that an institution's reputation could reciprocally affect the campus culture (e.g., students' perceptions of acceptable behavior at their institution). Indeed, peer behavior is significantly correlated with academic dishonesty (McCabe, Trevino, \& Butterfield, 2001). If students perceive their peers as engaging in academic dishonesty, then this behavior becomes more acceptable, and thus affects the entire institution.

Given the prevalence and consequences of academic dishonesty, researchers have investigated methods to reduce incidents of plagiarism. Such methods have included in-class activities and homework assignments (Barry, 2006; Landau, Druen, \& Arcuri, 2002; Schuetze, 2004). However, there remains a dearth of empirically supported online interventions to reduce incidents of plagiarism. Jackson (2006) developed an interactive, online tutorial and found an average $6 \%$ increase on an academic integrity quiz. However, this study did not utilize a between-subjects design to compare the results of this tutorial to another intervention. A literature review found only Belter and du Pre's (2009) study in which an intervention was implemented to a group of students and subsequent rates of plagiarism were compared to students not exposed to the intervention. The intervention consisted of an online academic integrity module. The module consisted of several sections including definitions of plagiarism and cheating, examples of original work and appropriate and inappropriate paraphrasing/citing, strategies to avoid plagiarism, and institution-specific penalties of academic dishonesty. Upon completion of the module, students completed a quiz to assess their understanding of the material. Students were required to score 100\% on the quiz; however, they were allowed to retake the quiz multiple times until all items were answered correctly. Students exposed to the intervention engaged in significantly fewer incidents of plagiarism compared to those not exposed to the intervention. These results are very promising. However, Belter and du Pre used a quasi-experimental design, which lacked randomization to groups. Specifically, the nonintervention comparison group was assessed during the Spring of 2004, while the other participants (who completed the academic integrity module and served as experimental condition) were assessed in the Fall and Spring of 2005, as well as the Fall of 2006. A replication of this research utilizing methodology to improve the internal validity (i.e., randomization to groups within the same semester and the same course) is necessary to garner more support for an online plagiarism module.

\section{CURRENT STUDY}

The current study extended the work of Belter and du Pre (2009) by comparing an online academic integrity tutorial against a pre-recorded online academic integrity lecture administered to randomized groups during one academic semester. We hypothesized that students randomized to receive the tutorial (i.e., an online module which included specific examples of original work, correctly cited or paraphrased work, and incorrectly cited or plagiarized work) would exhibit fewer incidents of plagiarism compared to the comparison group who received the lecture (i.e., a pre-recorded online academic integrity lecture narrated by the course instructor). Our rationale for this hypothesis is that the online tutorial contained more specific information regarding plagiarism and how to avoid plagiarizing compared to the pre-recorded lecture. A secondary hypothesis was that the students in the tutorial group would complete an academic integrity quiz in fewer attempts than the comparison group. Our rationale for this hypothesis is that students exposed to more specific content regarding plagiarism would make fewer mistakes when completing the quiz and thus, require fewer attempts to complete the quiz with $100 \%$ accuracy, compared to student who listened to the pre-recorded lecture. Thus, the current study aims to extend the Belter and du Pre (2009) study, with the addition of randomization to groups, and the use of a single instructor in one course during one semester to reduce potential confounding variables. 


\section{METHOD}

\section{Participants}

The participants consisted of 33 undergraduate students enrolled during Fall 2011 in a one-credit hour introductory-type course required of all psychology majors at a science and technology university. Demographic data available for 20 participants indicated $70 \%$ of participants were Caucasian, 52\% were female and participants were at least 18 years old $(M=21.25, S D=5.22)$. These participants included $35 \%$ freshmen, $13 \%$ sophomores, $44 \%$ juniors, and 9\% seniors. The mean GPA was $2.91(S D=0.72)$.

On the first day of class, students were informed of the opportunity to participate in the study. Although every student was required to participate in an academic integrity educational exercise (either the tutorial or the prerecorded lecture) and to complete a corresponding quiz with $100 \%$ accuracy, the data include only information from those students who gave informed consent (92\% of students enrolled in the course). No inducement was offered to the participants and the institutional review board approved the study.

\section{Measures}

Participants were assessed with the following measures: overall course performance (i.e., course percentage), indication if plagiarism occurred on a course assignment (determined by the course instructor), and number of attempts at completing the academic integrity quiz with $100 \%$ accuracy (determined by the tracking function on the course management website).

\section{Procedures}

Participants were randomized to two groups. The experimental group completed the online tutorial. This tutorial was a modified version of the Belter and du Pre (2009) module. The modification reflected the current study's institutional policies and procedures regarding academic dishonesty. Otherwise, the content remained the same as established by Belter and du Pre. Students were required to read information that defined plagiarism, compared examples of original versus plagiarized works, and included specific tips of how to avoid plagiarism (i.e., do not cut and paste, paraphrase properly, credit the original author, use quotation marks, do not over-rely on direct quotes, be able to produce resources, do not give your work to other students, document contribution of group members, and contact the course instructor for clarification as needed). Students also read information that defined cheating and included specific examples of how to avoid cheating (i.e., review the course syllabus, do no procrastinate, do not cut corners, do not allow others to complete your work and do not complete others work for them, do not use additional resources unless authorized by the instructor, do not allow others to cheat, do not associate with those who cheat, develop a personal commitment to integrity).

The comparison group listened to a pre-recorded online PowerPoint lecture narrated by the course instructor via Camtasia. The lecture reflected content typically covered in class by the instructor such as definitions of academic misconduct, institutional policies and procedures, and examples of what constituted the different types of academic dishonesty (i.e., not properly citing other's work is plagiarism), but did not provide specific written examples demonstrating plagiarized work that students could compare to the original work, or detailed tips on how to avoid plagiarism. Thus, the pre-recorded lecture provided fewer details and examples with regard to academic dishonesty and how to avoid plagiarism compared to the online tutorial.

After completing one of the educational exercises, participants completed a demographics survey and the 11-item quiz created and used by Belter and du Pre (2009). Participants were required to complete the quiz with $100 \%$ accuracy. Participants had unlimited opportunities, until the fifth week of school, to complete the quiz in order to achieve a score of $100 \%$. The tutorial and pre-recorded lecture, as well as the corresponding quiz, were accessible via the course management website, Blackboard. Student performance on the quiz was synchronized to the instructor's grade book and the number of attempts to complete the quiz was monitored via Blackboard. 


\section{RESULTS}

Individual t-tests and chi square analyses were conducted to assess differences in class status, GPA, number of quiz attempts, and gender between the tutorial and lecture conditions. There were no significant differences in class status, number of quiz attempts, GPA, or gender between the two groups.

To detect incidents of plagiarism on short, weekly assignments in the course, the course instructor compared the student work to the assigned website or book chapter and utilized Safe Assign, a program to detect plagiarism. Generally, the students who plagiarized copied sentences from the website or text verbatim without using quotations marks. It is possible a few students plagiarized, but were not detected; however, the writing style of plagiarized work was generally notably different from the writing style of the students.

The data for incidents of plagiarism were dichotomous, either participants did not plagiarize, or they plagiarized only once. Therefore, a chi square analysis was conducted to assess differences in the frequency of academic integrity incidents between the groups. There were no statistically significant differences in incidents of plagiarism between the groups $\left(\chi^{2}(1, N=33)=.081, p=.78\right)$ (tutorial: 5 of 17; pre-recorded lecture: 4 of 16). In addition, course performance was not significantly correlated with group, incidents of plagiarism, or number of quiz attempts. Yet, there was a significant positive relation between the number of quiz attempts (range 1-9) and the incidents of plagiarism $(r(31)=.388, p=.03)$.

\section{DISCUSSION}

Plagiarism is a significant problem, which not only affects the offending student, but the plagiarized party, the faculty, and the institution. However, there are few empirically supported, online interventions aimed at reducing incidents of plagiarism. The current study attempted to improve upon previous research methodology investigating the effect of an online tutorial to reduce rates of plagiarism (Belter \& du Pre, 2009) by incorporating randomization to groups and standardizing the assessment across a single course and instructor during one academic semester.

The data did not support either hypothesis; there were no significant differences in the incidents of plagiarism between the online tutorial and pre-recorded lecture groups, and the online tutorial group did not take fewer attempts at the quiz. Perhaps these results differ from the Belter and du Pre study due to the smaller sample size, type of course, differences in the comparison groups, or the finding that the two presentation methods are equally effective.

There was a significant positive correlation between the number of quiz attempts and whether plagiarism occurred. This association between quiz attempts (range 1-9) and plagiarism incidents may suggest that students who do not thoroughly understand academic integrity, regardless of presentation format, not only require more attempts to master an academic integrity quiz, but also engage in plagiarism. Perhaps an underlying factor among these students is a lack of intrinsic motivation, the desire to learn for the sake of learning, rather than learning to avoid punishment (i.e., poor grades). This association may speak about the students themselves, and whether they are mastery- or performance-oriented. A mastery-oriented individual has a desire to acquire knowledge and improve as a student, whereas a performance-oriented individual simply wants to be judged in a positive light and avoid being judged negatively by others (Darnon \& Butera, 2007). As mentioned previously, if the student simply wished to avoid punishment (i.e., pass the quiz by trial and error until a $100 \%$ was accomplished), then he or she would more likely be performance-oriented rather than mastery-oriented. However, if the student actually paid attention to the material out of a sincere interest to learn and managed to pass the quiz on their first or second try, they would better exemplify a mastery-oriented learner.

\section{Limitations and Future Research}

The limitations of this research include a small sample size, which may affect the statistical power to find differences between the groups. In addition, while the study was conducted at a science and university campus, the sample consisted of psychology majors. Therefore, perhaps the tutorial would need to be modified again to address 
students of various fields. As previously mentioned, plagiarism is a significant problem in engineering labs (Parameswaran \& Devi, 2006). The tutorial could be modified to target undergraduate engineering students (i.e., shifting examples within the module from papers to labs, tests, and homework) and thus, be more representative of an engineering student's curriculum.

Additionally, differences in the comparison groups between the current study and Belter and du Pre's work may account for the findings. Belter and du Pre utilized a nonintervention comparison group-the students in this group (Spring 2004) did not complete any academic integrity module compared to the students in the intervention group (Spring 2005, Fall 2005 and 2006). The current study, in seeking to evaluate students within one course during one semester, randomized students to receive some type of academic integrity training-either a pre-recorded online lecture or an online academic integrity tutorial which included specific examples of original versus plagiarized works. The authors choose this methodology in part due to the institution's policy regarding mandatory reporting of academic dishonesty. We chose not to create a condition in which students received no exposure to academic integrity, potentially setting the scene for the instructor to report dishonesty by a student who had received no education. However, in choosing this methodology, the current study lacks a true nonintervention group. Therefore, perhaps Belter and du Pre's study suggests the benefits of incorporating an online academic integrity tutorial over no intervention at all, but the current study suggests that an online tutorial and a pre-recorded lecture produce equivalent results. Future research should compare three conditions: the online tutorial, a pre-recorded lecture, or no intervention.

\section{Implications}

Although these data do not reveal an effect of the online tutorial, it appears that it is no worse than a prerecorded lecture. That is to say, at the very least, an online academic integrity tutorial or a recorded lecture on ethics could be implemented by faculty as an alternative to live classroom lectures or the preparation time required to record a lecture.

\section{AUTHOR INFORMATION}

Amber M. Henslee, Ph.D., is an Assistant Professor in the Department of Psychological Science at Missouri University of Science and Technology. Her current research interests include college student health-related behaviors, and the scholarship of teaching and learning. E-mail: hensleea@mst.edu (corresponding author)

Jacob Goldsmith is a graduate of Missouri University of Science and Technology with Bachelor's of Science in Psychology. He is currently pursuing his Master's degree in Exercise Physiology at Florida Atlantic University. His current research interests include resistance training, periodization, and hypertrophy. E-mail: jagkp4@gmail.com

Nancy J. Stone is professor and chair of the Department of Psychological Science at Missouri University of Science and Technology. She also is director of the M.S. in Industrial-Organizational Psychology program. E-mail: nstone@mst.edu

Merilee Krueger is an Associate Teaching Professor and has been part of the Department of Psychological Science at Missouri University of Science and Technology for more than twenty years. She obtained her Master's Degree from the University of Nebraska in Cognitive Development Psychology. E-mail: krueger@mst.edu

\section{REFERENCES}

Barrett, R., \& Cox, A. L. (2005). 'At least they're learning something': The hazy line between collaboration and collusion. Assessment \& Evaluation In Higher Education, 30, 107-122. doi:10.1080/0260293042000264226

Barry, E. S. (2006). Can paraphrasing practice help students define plagiarism? College Student Journal, 40(2), 377-384. 
Belter, R. W., \& du Pré, A. (2009). A strategy to reduce plagiarism in an undergraduate course. Teaching Of Psychology, 36, 257-261. doi:10.1080/00986280903173165

Darnon, C., \& Butera, F. (2007). Learning or succeeding? Conflict regulation with mastery or performance goals. Swiss Journal Of Psychology/Schweizerische Zeitschrift Für Psychologie/Revue Suisse De Psychologie, 66, 145-152. doi:10.1024/1421-0185.66.3.145

Elander, J., Pittam, G., Lusher, J., Fox, P., \& Payne, N. (2010). Evaluation of an intervention to help students avoid unintentional plagiarism by improving their authorial identity. Assessment \& Evaluation In Higher Education, 35, 157-171. doi:10.1080/02602930802687745

Ellery, K. (2008). Undergraduate plagiarism: A pedagogical perspective. Assessment \& Evaluation In Higher Education, 33, 507-516. doi:10.1080/02602930701698918

Guo, X. (2011). Understanding student plagiarism: An empirical study in accounting education. Accounting Education, 20, 17-37. doi:10.1080/09639284.2010.534577

Jackson, P. A. (2006). Plagiarism instruction online: Assessing undergraduate students' ability to avoid plagiarism. College \& Research Libraries, 67(5), 418-428.

Landau, J. D., Druen, P. B., \& Arcuri, J. A. (2002). Methods for helping students avoid plagiarism. Teaching of Psychology, 29(2), 112-115.

Liebler, R. (2009). Plagiarism and costs. College Student Journal, 43, 718-722.

McCabe, D., Trevino, L., \& Butterfield, K. (2001). Cheating in academic institutions: A decade of research. Ethics \& Behavior. 11, 219-232.

McKeachie, W.J., (2002). McKeachie's Teaching Tips: Strategies, research, and theory for college and university teachers. New York: Houghton Mifflin Company.

Newstead, S. E., Franklyn-Stokes, A., \& Armstead, P. (1996). Individual differences in student cheating. Journal Of Educational Psychology, 88, 229-241. doi:10.1037/0022-0663.88.2.229

Parameswaran, A., \& Devi, P. (2006). Student plagiarism and faculty responsibility in undergraduate engineering labs. Higher Education Research \& Development, 25, 263-276. doi:10.1080/07294360600793036

Pérez-Peña, R., (2012, August). Harvard students in cheating scandal say collaboration was accepted. The New York Times. Retrieved from http://www.nytimes.com/2012/09/01/education/students-of-harvard/

Schuetze, P. (2004). Evaluation of a brief homework assignment designed to reduce citation problems. Teaching of Psychology, 31(4), 257-259.

Szabo, A., \& Underwood, J. (2004). Cybercheats: Is Information and Communication Technology fuelling academic dishonesty?. Active Learning In Higher Education, 5, 180-199. doi:10.1177/1469787404043815

Yeo, S. (2007). First-year university science and engineering student's understanding of plagiarism. Higher Education Research \& Development, 26, 199-216. doi:10.1080/07294360701310813 